\title{
El impacto de las políticas de planificación regional en el desarrollo del Caribe mexicano \\ DOI: $10.22403 /$ UQROOMX/TYP03/03
}

Maribel Lozano Cortés*

RESUMEN

Alejandro Ramírez Loría

Este trabajo pretende explicar las políticas de planificación regional en el Caribe mexicano, caso concreto Cancún, para analizar en qué medida ha servido de polo de crecimiento. Los antecedentes más importantes que inspiraron la planificación regional latinoamericana se encuentran en la concepción del desarrollo integrado de cuencas hidrográficas aplicada a los Estados Unidos en 1933. Posteriormente, la implementación de estrategias y políticas encaminadas a reducir las disparidades regionales recorrieron varias etapas, pudiéndose distinguir entre las principales teorías: la económica espacial neoclásica, la macroeconomía regional de vertiente keynesiana y la teoría de los polos de desarrollo derivada de Perroux.

Estas políticas públicas de planificación regional en América Latina han sido objeto de estudio y de evaluación durante años. Sin embargo, entre principios de los años setenta hasta mediados de los ochenta, en la región del Caribe mexicano la teoría de los polos de crecimiento como fundamento racional de la planificación regional pasó por el ciclo vital de nacimiento, auge y declinación, para resurgir de nuevo en la década de los noventa como un medio de atracción de grandes empresas e incentivo de la actividad económica local.

Palabras | Desarrollo local, planificación regional, política pública.

CLAVE

*Universidad de Quintana Roo / mlozano@correo.uqroo.mx 


\section{Antecedentes}

\section{Sobre el concepto de región}

De las numerosas definiciones que existen acerca del concepto de región, predomina el criterio de unidad formal y homogénea. A partir de este punto, las definiciones van evolucionando de acuerdo con las distintas formas de enfocar el pensamiento geográfico; una de las más simples proviene de la Escuela Objetiva Soviética, donde J. Marinov la explica como "un complejo de territorio y economía que ha desarrollado lazos internos de producción y que se especializa en escala nacional” (Bassols, 1993: 133).

Palacios (1993: 104), quien considera importante diferenciar entre el término región como vocablo, que denota la idea de ámbito, y lo que de manera más específica constituye el concepto de región en ciencias sociales, llega a la conclusión de que una región es una porción de la realidad geográfica en cuyo interior prevalecen alguno o algunos atributos que le confieren homogeneidad suficiente para distinguirse de otras y así tener identidad y existencia propias.

Para Helmsing (1999: 16), quien enfoca su trabajo al estudio de teorías de desarrollo industrial regional (concentración de empresas), una región es un sistema económico coordinado. Y aunque la concentración geográfica de empresas industriales no es un fenómeno nuevo, para este autor el aspecto clave para alcanzar el crecimiento es que las políticas sectoriales y espaciales deben ser desarrolladas en conjunto y alrededor de regiones o unidades específicas.

\section{La teoría de los polos de crecimiento}

La teoría de los polos de crecimiento hace hincapié en los procesos de localización y en los procesos acumulativos. Se originió en la década de los cincuenta en los trabajos de Perroux, Boudeville, Myrdal y Hirschman, quienes se basaron en la teoría del desarrollo polarizado que orientó gran parte de los análisis y de las políticas de desarrollo regional en los años siguientes (Vázquez, 1997:6).

La idea principal de esta teoría es que los mecanismos de acumulación de capital producen un desarrollo desigual dentro del territorio; mientras que en unas cuantas ciudades se acumulan los beneficios, en el resto del país existe un marcado subdesarrollo. 
De esta manera, el concepto de polo de desarrollo ha sido definido por varios autores como aglomeración geográfica y desequilibrio industrial; otros conceptos similares son centros de crecimiento, áreas de crecimiento, núcleos de desarrollo, etcétera.

Para Hermansen (I986: II):

el concepto original de polos de desarrollo se contemplaba como una herramienta para el estudio de la anatomía del desarrollo económico en el espacio económico abstracto, pero con el transcurso del tiempo se ha ampliado considerablemente su alcance, ocupándose sintéticamente del problema del desarrollo social -por oposición al progreso económico- en un contexto sectorial, espacial y temporal simultáneo.

La teoría del desarrollo polarizado dio lugar a las políticas de polos de crecimiento o de descentralización concentrada en varias partes del mundo."El desarrollo local y regional debía hacerse a través de la atracción de las grandes empresas y la promoción de actividades industriales en un número reducido de ciudades intermedias dentro de la jerarquía urbana" (Vázquez, 1997: 7).

En México, a finales de la década de los sesenta, estudios económicos revelaron la importancia del turismo como una fuente importante de divisas y como motor del desarrollo económico de las regiones. Ante la ausencia de políticas económicas a largo plazo, se buscó diversificar la oferta turística existente a través del fomento de nuevos destinos que se construirían a partir de cero y que servirían como detonadores de la actividad económica regional.

Luego de evaluar docenas de ubicaciones potenciales, a principios de 1969 el Banco de México recomendó la creación de cinco centros turísticos integrales: Ixtapa, Los Cabos, Loreto, las Bahías de Huatulco y Cancún.

\section{El proyecto Cancún como polo de desarrollo}

\section{El inicio}

El proyecto Cancún se remonta a enero de 1970, cuando empiezan los primeros trabajos y se diseña el plan maestro de desarrollo que consideraba la construcción de una zona turística y otra habitacional para los residentes permanentes, y la construcción de un aeropuerto internacional. 
El año 1974 fue importante para Cancún, ya que el territorio de Quintana Roo se convierte en estado de la federación, se inaugura el aeropuerto internacional y empiezan a funcionar los primeros hoteles.

De acuerdo con la Oficina de Visitantes y Convenciones de Cancún, "Para 1976, Cancún se había consolidado como destino turístico con I8 000 habitantes, flujo migratorio estable, más de 5000 empleos, I 500 cuartos y más de 100000 visitantes en la temporada de invierno 1976-1977". A partir de entonces, se registra un despegue explosivo tanto en el aspecto económico como poblacional; actualmente, su población asciende a más de 500000 habitantes.

\section{Situación actual}

La planificación regional, entendida como un proceso mediante el cual se pretende reordenar el territorio para disminuir las disparidades regionales, ha estado vigente en el mundo por más de setenta años a pesar de sus contradicciones y la existencia persistente de las regiones y localidades en condiciones de pobreza extrema.

Existen problemas estructurales del desarrollo económico y social que han propiciado el desarrollo desigual de las regiones, como afirma Rolando Cordera (2002),y que no se pueden solucionar"desde arriba". Estos problemas estructurales han dado lugar a un proceso de terciarización de la economía y a una reducción significativa del sector primario. El cambio en la estructura del empleo se ha caracterizado por una disminución relativa del empleo primario e industrial y por un desplazamiento hacia los servicios, principalmente de baja productividad.

En el estado de Quintana Roo, particularmente originado por el desarrollo turístico de Cancún, se ha obtenido un crecimiento económico considerable en las últimas décadas. Sin embargo, la actividad económica se ha centrado en el turismo de manera casi natural y se han reducido las otras actividades; incluso el comercio se realiza con base en la expectativa del turista promedio y la especulación de la tierra se ha convertido en una forma de vida privilegiada. En los ejidos cercanos, la actividad económica ha dejado de ser la agricultura para dar paso a la especulación.

Se reproduce en Quintana Roo el patrón de desarrollo regional que se caracteriza por una elevada concentración económica y poblacional en unas cuantas localidades urbanas. La distribución territorial de la población y de las actividades económicas presenta agudos contrastes, reflejados en puntos 
extremos tanto de dispersión y concentración como de pobreza y auge. De esta manera, en el XII Censo general de población y vivienda, 2000 (INEGI, 200I), se observa que el estado cuenta con 2167 localidades con las siguientes características poblacionales:

I 834 localidades de I a 49 habitantes

57 localidades de 50 hasta 99 habitantes

153 localidades de 100 hasta 499 habitantes

67 localidades de 500 a 999 habitantes

33 localidades de 1000 a 1999 habitantes

23 localidades con 2000 o más habitantes

Estos datos demuestran la alta dispersión poblacional que existe en el ámbito rural lo que, aunado a las condiciones de pobreza predominantes en estas comunidades, hace fácil deducir que las políticas de planificación para la región, basadas en el desarrollo del polo turístico de Cancún, no han dado los resultados esperados.

De hecho, el número de empresas registradas al 2004 en el Sistema de Información Empresarial Mexicano (SIEM), nos muestran que 50\% se localiza en el municipio Benito Juárez (Cancún), mientras que otro $28 \%$ se ubica en los municipios eminentemente turísticos de Cozumel y Solidaridad (véase tabla I).

El mayor problema detectado es la incapacidad de lograr un desarrollo más equitativo entre el del polo turístico de Cancún y el de las comunidades rurales de Quintana Roo, debido principalmente a que la mayoría de los bienes y servicios necesarios para el abastecimiento del sector turístico de Cancún son importados de otros estados, mientras que el consumo de productos locales es casi imperceptible.

Sin embargo, de las 27981 empresas registradas, 845 se encuentran en el sector industrial, la mayor parte corresponden al sector de la construcción. Estas empresas, paradójicamente, a pesar de que no encuentran en el estado su materia prima principal, como el cemento, son los principales demandantes de mano de obra local.

Esto ha dado origen a otro tipo de fenómeno observable: la migración de quienes, atraídos por las oportunidades de empleo que ofrece Cancún, se trasladan continuamente en busca de mejoría en sus condiciones de vida, enfrentando todo tipo de riesgos. 
Tabla I. Empresas del estado de Quintana RoO Registradas en el sIem

\begin{tabular}{lr}
\hline Municipios & Empresas \\
\hline Cozumel & 3078 \\
Othon P. Blanco & 4028 \\
José Ma. Morelos & 560 \\
Benito Juárez & 13992 \\
Felipe Carrillo Puerto & 648 \\
Isla Mujeres & 471 \\
Lázaro Cárdenas & 584 \\
Solidaridad & 4620 \\
\hline Total & 27981 \\
\hline
\end{tabular}

Fuente: Elaboración propia a partir de estadísticas 2004 del SIEM.

A tal grado ha llegado esta migración constante de personas hacia Cancún, que el mosaico de culturas y costumbres es completamente heterogéneo ya que la población nativa se encuentra en menor proporción a pesar de tener un crecimiento poblacional de los más elevados a nivel nacional.

Además, como se ha afirmado, la consolidación del Proyecto Cancún abrió nuevas posibilidades de desarrollo en sus alrededores inmediatos y ahora tenemos lo que se conoce como Riviera Maya. La Riviera Maya ha experimentado un ritmo de crecimiento muy explosivo, mucho mayor que el de Cancún. Esta zona registra actualmente el mayor crecimiento demográfico de América Latina y el más alto porcentaje de inmigración de todo el país, concentrado todo ello en una sola actividad: el turismo.

Este crecimiento poblacional no estaba previsto cuando se planificó el desarrollo turístico de Cancún y aunque se invirtieron grandes sumas en infraestructura, agua potable, alcantarillado, energía eléctrica, urbanización, etc., no se logró cubrir la demanda. En la Riviera Maya, la inversión en infraestructura es mucho menor que la que se realizó en Cancún y la demanda de servicios urbanos es un problema severo, de manera que se tienden a agudizar aún más los problemas del desarrollo. 


\section{Perspectivas para el desarrollo local}

Estas políticas públicas de planificación regional en América Latina han sido objeto de estudio y de evaluación durante años, por lo que las críticas han sido constantes. Boisier (1993: 3 I I) señala que la separación entre el estado y la región (sujeto y objeto) "condujo a considerar el desarrollo regional como un proceso centralizado, impuesto de arriba hacia abajo, dependiente de los vaivenes del Estado y del sector público, con regiones completamente receptivas y pasivas, es decir como un proceso totalmente exógeno y dependiente desde la perspectiva regional".

De la misma forma, pero a nivel internacional, Hermansen (1986: I7) hace notar que "los modelos ensayados no han sido capaces de lograr su objetivo; lo han conseguido en forma parcial y muchas veces confinado a regiones muy específicas; se han limitado en la etapa de confección de planes; han servido de simple eslabón para la planificación nacional"; a la vez, señala que la mayor parte de las teorías de desarrollo regional se llevan a cabo en países industrialmente avanzados $y$, por lo tanto, existe una carencia de teorías formuladas con referencia directa a la situación y los problemas de países subdesarrollados.

Existe una pregunta fundamental que no ha tenido una respuesta convincente para los estudiosos del crecimiento económico en el Caribe mexicano, ¿por qué la dirección deliberada del desarrollo económico, mediante la creación del polo de crecimiento de Cancún, no ha podido generar desarrollo en los demás municipios del estado de Quintana Roo?

Una primera explicación podría consistir en que tal vez el gobierno no ha creado las condiciones propicias para el crecimiento en los municipios rurales; en particular, a través de inversión en infraestructura que motive al sector privado a realizar inversiones productivas en el campo, en fábricas, servicios, entre otros, todo ello asociado con la inversión que el gobierno hubiese realizado previamente.

Por otra parte, en un mundo crecientemente integrado en el que un inversionista mexicano o extranjero tiene múltiples opciones para invertir es indispensable que exista un régimen legal confiable además de adecuado para que el crecimiento económico sea posible. El crecimiento depende enteramente de la inversión privada y ésta sólo se da en la medida en que los empresarios encuentran condiciones propicias para planear a largo plazo. En Quintana Roo no han existido planes de fomento al desarrollo local que vayan más allá de los 
seis años que duran los periodos gubernamentales. Las reglas y los apoyos a la producción cambian constantemente, por lo que el potencial inversionista difícilmente arriesga su dinero en proyectos poco redituables.

Sin embargo, la formación de diversos conglomerados de empresas que fomentan las economías de aglomeración, constituye una ventaja competitiva de la región; este tipo de economías se establecen cerca de los agentes de una región y determinan los sectores complementarios.

La forma de hacer política regional basada en el concepto "de abajo hacia arriba" puede facilitar una visión común del futuro y por lo tanto, permite la identificación de la política y de las estrategias capaces de ofrecer soluciones a los problemas estructurales más que a los coyunturales, para poder así enfocar los recursos hacia objetivos claros de desarrollo.

Las teorías de desarrollo local no niegan la importancia de utilizar recursos exógenos para favorecer el desarrollo endógeno, pero "el desafío pasa entonces por qué tanto son los actores capaces de utilizar los recursos que pasan, y quedan, en su ámbito territorial, para mejorar las condiciones de vida de los habitantes" (Gallicchio, 2004: 8)

Un impedimento para el desarrollo local fue durante muchos años la lejanía de las comunidades con las regiones centrales o centros de crecimiento, pero que en nuestros días, con las modernas vías de comunicación, permiten trasladar industrias completas a regiones alejadas. Con las vías de comunicación existentes, las distancias dejan de ser factor en contra del desarrollo local, ya que fragmentos de territorio con condiciones económicas y sociales muy diversas pueden articularse a través de redes específicas de producción.

\section{FUENTES CONSULTADAS}

Bassols Batalla,A.(1993).“La división económica regional de México”, en Héctor Ávila (comp.). Lecturas de análisis regional en México y América Latina. México: Universidad Autónoma de Chapingo, I2I-I53.

Boisier, S. (1994). "La construcción social del regionalismo latinoamericano. Escenas, discursos y actores". Reforma y Democracia, Caracas, Venezuela: CLAD, núm. 2, julio de 1994, 191-222.

(1993).“La articulación estado-región: clave del desarrollo regional”, en Héctor Ávila (comp.). Lecturas de análisis regional en México y América 
Latina. México: Universidad Autónoma de Chapingo, 309-346.

Cordera, R. (2002). “Desigualdades regionales”, [en línea]. Disponible en: http://www.rolandocordera.org.mx [2005, 25 de febrero].

Corragio, J. L. (1997). "Perspectivas del desarrollo regional en América Latina”.

Conferencia inaugural presentada en el III Seminario Internacional Estado, región y sociedad emergente. Recife, Brasil, 9 de diciembre de 1997.

- et al. (1993).“Experiencias de planificación regional en América Latina. Una teoría en busca de una práctica”, en Héctor Ávila (comp.). Lecturas de análisis regional en México y América Latina. México: Universidad Autónoma de Chapingo, 195-237.

Gallicchio, E. (2004), “El desarrollo local en América Latina. Estrategia política basada en la construcción de capital social". Ponencia presentada en el Seminario Desarrollo con inclusión y equidad:sus implicaciones desde lo Local, realizado por SEHAS en Córdoba, Argentina, en mayo de 2004.

Helmsing, A. (1999). "Teorías de desarrollo industrial regional y políticas de segunda y tercera generación”. Revista Latinoamericana de Estudios Urbanos y Regionales (Eure), septiembre, 25, 75, 5-39.

Hermansen,T.(1986).“Polos y centros de desarrollo en el desarrollo nacional y regional. Elementos de un marco teórico”, en A. R. Kuklinski (comp.). Polos y centros de crecimiento en la planificación regional. México: Siglo XXI, P. I I-82.

Hiernaux, D. y Lindon, A. (1997). “En qué sentido las desigualdades regionales?” Revista Latinoamericana de Estudios Urbanos y Regionales (Eure), 22, 68, 29-43.

INEGI (200I). XII Censo general de población y vivienda, 2000. Aguascalientes: INEGI.

Mattos de, Carlos (1993). "Paradigmas, modelos y estrategias en la práctica latinoamericana de planificación regional”, en Héctor Ávila (comp.). Lecturas de análisis regional en México y América Latina. México: Universidad Autónoma de Chapingo, 27I-307.

Merlin, P. (2002). "L Aménagement du territoire” Disponible en http://www. cafe-geo.net/article.php3?id_article=43 I [2005, I I de marzo].

Oficina de Visitantes y Convenciones de Cancún (2004), [en línea]. Disponible en http://www.cancun.info [2005, I5 de marzo]. 
Palacios,J.(1993).“El concepto de región: la dimensión espacial de los procesos sociales”, en Héctor Ávila (comp.). Lecturas de análisis regional en México y América Latina. México:Universidad Autónoma de Chapingo, IOI-II9.

Perroux, F. (1993).“Notas sobre el concepto polos de crecimiento”, en Héctor Ávila (comp.). Lecturas de análisis regional en México y América Latina. México: Universidad Autónoma de Chapingo, 83-97.

Rofman,A. (1993).“Desigualdades regionales y concentración económica. El caso argentino”, en Héctor Ávila (comp.). Lecturas de análisis regional en México y América Latina. México: Universidad Autónoma de Chapingo, 239-270.

Sistema de Información Empresarial Mexicano (2005), [en línea]. Disponible en: http://www.siem.gob.mx [2005, I7 de marzo].

Vázquez Barquero, A. (1997). "Gran empresa y desarrollo endógeno: La convergencia estratégica de las empresas y territorios ante el desafío de la competencia", Revista Latinoamericana de Estudios Urbanos y Regionales (Eure), diciembre, 23, 70, 5- 18. 